\title{
Taking a Holistic Perspective on Technical Communication and Lean
}

DOI: 10.12776/QIP.V19I2.608

Pernilla Ingelsson, Ulrica Löfstedt, Ingela Bäckström, Lena-Maria Öberg

Received September 04 2015, Accepted October 09 2015, Published 31 December 2015

\begin{abstract}
Purpose: The purpose of this paper is to present best practices and areas of improvement in Technical Communication (TC) analyzed with Lean values as a base. The purpose is also to analyze the results from a holistic perspective using the Synergy-4 model, a multi-perspective approach which considers four different spheres of an organization at a time in order to discover synergies.

Methodology/Approach: To fulfill the purpose, 15 interviews in four different companies were conducted. These were then analyzed and the results were categorized into a number of predefined Lean areas. The results from the Lean values were then further analyzed with the Synergy-4 model as a base.

Findings: Taking a Lean perspective could enhance the status of TC with regard to finding ways to incorporate the customer's voice more clearly when it comes to strengthening the role of TC. The result from the analyses indicates that Lean and Synergy-4 can enrich each other.
\end{abstract}

Category: Case study

Keywords: Lean; Quality Management; system thinking; Technical Communication 


\section{INTRODUCTION}

Lean is a Quality Management (QM) initiative that focuses on maximizing customer value and minimizing different kinds of waste, see e.g. Womack and Jones (2003) and Liker (2004). A culture based on values like long-term thinking, a system view and continuous improvements needs to be created (Bicheno and Holweg, 2009). To achieve this, a number of methods and tools are used, e.g. value flow analysis, standardization, $5 \mathrm{~S}$ etc., but the most important thing is to first stand back and look at the system and then apply a method of thinking adjusted to the organization's prerequisites (Ibid.).

Technical Communication (TC) is facing many challenges at present and will continue to do so in the future. In this article, TC is seen as information exchange between producers of technical products and their users and can typically be user manuals, maintenance instructions, handbooks, descriptions and assembly lists and so on. TC makes it possible to introduce, use, maintain and phase out products in a secure and sustainable way (Asproth, 2011). However, it is often seen as simply an obligation, a rather secondary product and something which one is unfortunately obliged to include with technical artefacts, i.e. a necessary but insignificant appendage to product development. This influences the possibilities to make investments and to increase the quality of TC.

Nowadays, there is also a lack of evaluation and measurement of customer opinions about the TC produced (Bäckström et al., 2014). Despite this, however, TC has the potential to create added value and to increase the perceived quality of the product. TC is a part of the whole product, influencing different kinds of users and several parts of the organization and the synergy effects reached by high-quality TC are often disregarded. A system approach can be successful for TC and is also at the very essence of Lean, which emphasizes the supply chain, and where the production within the organization is part of a value stream from the sub-suppliers to the ultimate customer. It has been indicated that using Lean in the production has resulted in an enhancement of the added value of TC.

Accordingly, the purpose of this paper is to present best practices and areas of improvement in Technical Communication (TC) analysed with Lean values as a base. The purpose is also to analyse the results from a holistic perspective using the Synergy-4 model (Holmberg, 2001), a multi-perspective approach which considers four different spheres of an organization at a time in order to discover synergies.

\subsection{Lean}

On the basis of Toyota's internal training document, 'The Toyota Way', Liker (2004) describes Lean as 14 principles divided into four parts of a pyramid: the ' 4 P' model. The bottom of this pyramid and the most important factor for success is the value 'Long-term thinking'. Long-term thinking is incorporated into one of The Toyota Way's core values 'challenge', where this value stands 
for maintaining a long-term vision and striving to meet all challenges with the courage and creativity needed to realize that vision (Bicheno and Holweg, 2009). Along with long-term thinking, a system approach is essential for Lean. According to Bicheno and Holweg (2009), this can be defined as focusing on the organization as a whole before paying attention to the parts. Lean emphasizes the supply chain, where the production within the organization is part of a value stream from the sub-suppliers to the ultimate customer (Womack and Jones, 2003). Managing the organization as a system includes, among other things, adopting an outside-in perspective and having a design based on customer demand, value and flow (Seddon, 2005).

The customer and creating value for the customer are central to Lean. The reason for applying it has to be for the benefit of the customer, not for internal company reasons (Emiliani, 2010). Bicheno and Holweg (2009) extract 25 common themes, from examining a number of books on Lean, where the principal theme is the external customer. According to Womack and Jones (2003), the critical starting point for Lean is value, which can only be defined by the ultimate customer as the whole offer to the customer, not as simply optimizing part of the delivery. Both Womack and Jones (2003) and Liker (2004) are clear about the importance of defining value from a customer point of view, arranging the processes, or value streams, to create this value and then making the value flow through the processes. In this value flow, the information flow should also be included since these are two sides of the same coin (Rother and Shook, 2004). Lean can be seen as a change from resource focus to customer focus and the processes are central for creating value for the customers (Modig and Åhlström, 2012).

Something many people associate with Lean is the elimination of waste. Value is seen as the opposite of waste and waste elimination is seen as a means to achieve Lean - but not as an end in itself (Bicheno and Holweg, 2009). The elimination of waste is closely linked to creating flow in an organization's processes (Womack and Jones, 2003; Liker, 2004). To remove the waste and improve the flow, it is important to understand the current status in terms of waste and flow and that is accomplished through visualization and measuring (Petersen and Wohlin, 2011). Bicheno and Holweg (2009), list the traditional seven types of waste defined by Taichii Ohno as: overproduction, waiting, unnecessary motion, transporting, over-processing, unnecessary inventory and defects. Very often an eighth type of waste is added, that of untapped human potential.

According to Emiliani (2010), the two main values that need to permeate a Lean organization are continuous improvement and respect for people. According to Bicheno and Holweg (2009), the power of Lean lies in learning from mistakes and continuously improving, continuously learning. Looking at Liker's (2004) 4P pyramid, at the top is Problem Solving (Continuous Improvement and Learning), which is seen as the final step where the organization is continuously solving root problems, which in turn drives organizational learning. 
The administrative processes in organizations are also under scrutiny and massive amounts of waste have been found (Emiliani, 1998). He asserts that the engine for further improvement in business as a whole is the practice of Lean behaviors, performance by elimination of waste within functions and the sustaining of internal and external interfaces.

\subsection{Technical Communication}

Technical Communication (TC) is a comprehensive concept including different kinds of manuals and maintenance instructions as well as, for example, drawing plans, catalogues for spare parts and material for training. TC is an important part of the process and makes it possible to introduce, use, maintain and phase out technical artifacts in a safe, beneficial and sustainable way (Asproth, 2011). It has been transformed from communication about technology to communicating about and through technology. This means, according to Johnson-Eilola and Selber (2013), that TC has become both a process and a product and not something that it is possible to manage as a separate part of the product. Instead it should be viewed integral to the product.

Our standpoint is based upon the belief that TC has the potential to create surplus value for the customers and for the enterprises. This standpoint is based on the trend whereby technical communicators nowadays also have competence (or at least should have) in the information economy (Hart-Davidson, 2013), i.e. technical communicators have competence in how to work with, for example, single sourcing and re-use of information. This creates a positive potential since it could move the technical communicators higher up the value chain. Information is thereby seen as one of the most valuable factors and its value is directly influenced by 'how it can be understood and used by others' (HartDavidson, 2013, p. 57). This shift is however easiest to see in organizations that have TC as their primary product, whereas a lot of organizations often see it as a secondary product and in some cases even as a necessary evil (Ibid.). This view of TC is affecting not only its status but also the technical communicators producing it (Bank, Löfstedt and Nyström, 2013). One reason why its status is low is probably connected to the fact that TC as a field is unknown and there is a lack of a comprehensive definition (Selfe and Selfe, 2013). This view is also affecting the possibilities for quality work in the field, and today it is difficult to know if the customers really get the TC that they need. Hart-Davidson (2013) claims that listening to the users should be the issue that the organization gives the highest priority to. Unfortunately this is not always the case.

The development whereby TC will become more seamlessly integrated into the product also means that the field has become more complex (Johnson-Eilola and Selber, 2013). Nyström and Asproth (2013) have stated that this increased complexity also puts new demands on how to work with TC. The work has to be performed in a more structured way. The users are disparate and this makes it necessary to work more with, for example, the requirement analysis. According to Öberg $(2009 ; 2011)$, many customers are unfamiliar with making demands in 
the field of TC, which also weakens its position. The lack of requirements and constraints that make demands on information technology makes it problematic to measure and monitor the extent to which the customers get what they need.

An approach to holistically analyzing the areas of TC and Lean could be beneficial in order to find synergies between the two areas, since a system view is present within both.

\subsection{Synergy-4 model}

One way to do this is to use the Synergy-4 model. This is a multi-perspective approach considering four different spheres of an organization at a time and is seen as a part of a model for developing towards a learning organization; Syntegrity-4 (Holmberg, 2001). The spheres are competence (human skills), management (doctrine), organization and procedures, and technology (technical infrastructure) (see Figure 1). These overlapping spheres of an organization interact and there are interdependencies between them (Holmberg, 2001).

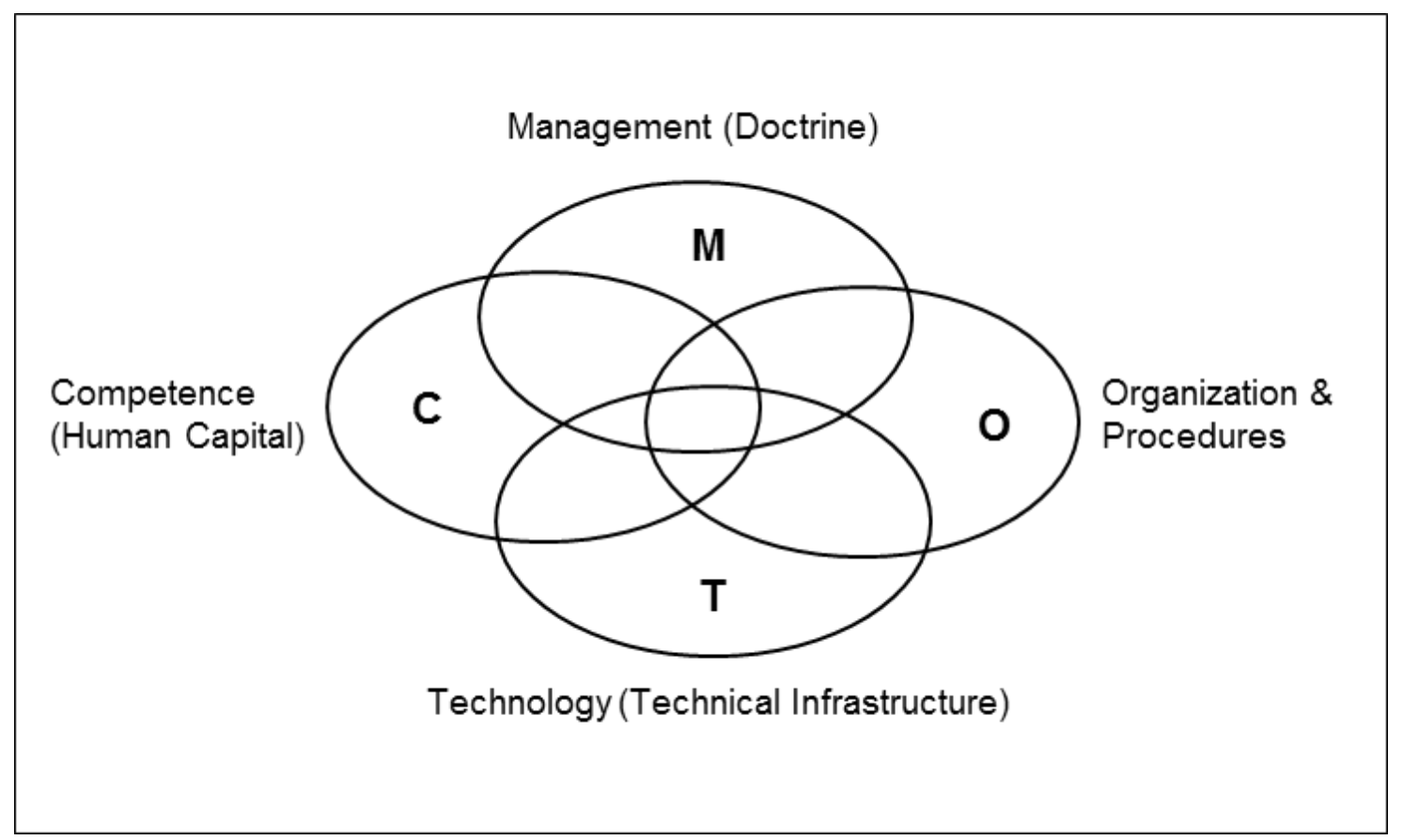

Figure 1 - Synergy-4 (Holmberg, 2001)

Synergy-4 is an approach with potential for developing successful organizations by juxtaposing essential spheres in an organization and the synergetic effects arising in the overlap between two, three, and/or four spheres. Combining the spheres would entail synergetic effects in the organization (Holmberg, 2001). Borglund, Slumpi and Öberg (2010) considered the synergies difficult to discover and evaluate. According to their study, there has not been any research concerning the synergies yet. 


\section{METHODOLOGY}

In order to identify best practices and areas of improvement in TC based on Lean, interviews in four companies that work with technical communication in different ways were conducted (see Figure 2). Thirteen were conducted on-site and the remaining two were conducted by telephone. All were recorded. The interviews were semi-structured and based on an interview guide, which was sent out to the companies in advance. The questions for the guide were developed by the research team and then categorized from a Lean perspective. The categories agreed upon were the Lean values: customer perspective, long-term thinking, system view and continuous improvement and the Lean methodologies: value flow analysis, standardization and measurements. After the interviews were conducted, they were all transcribed verbatim. They were then analysed based on the transcribed interviews. All the transcripts were read through by all of the members in the research team and each identified good practice and improvements. Each interview was compiled by the research team in workshops where the identified best practice and improvements were discussed and then categorized into the seven categories.

In order to analyse the results from a wider system perspective, the Lean values were further analysed with Synergy-4 as a starting-point. The best practices and areas of improvement identified were categorized according to the four spheres and the overlapping spheres in the model. The four spheres from the Synergy-4 model are interpreted as: $(\mathrm{M})$ : Management of direction and prerequisites in the organization; (O): How to organize and how each task is performed (methods of working); (C): Development and use of competence and learning in the organization; and (T): Technical solutions which are available and used. The categorization was done through consensus discussion in the research group.

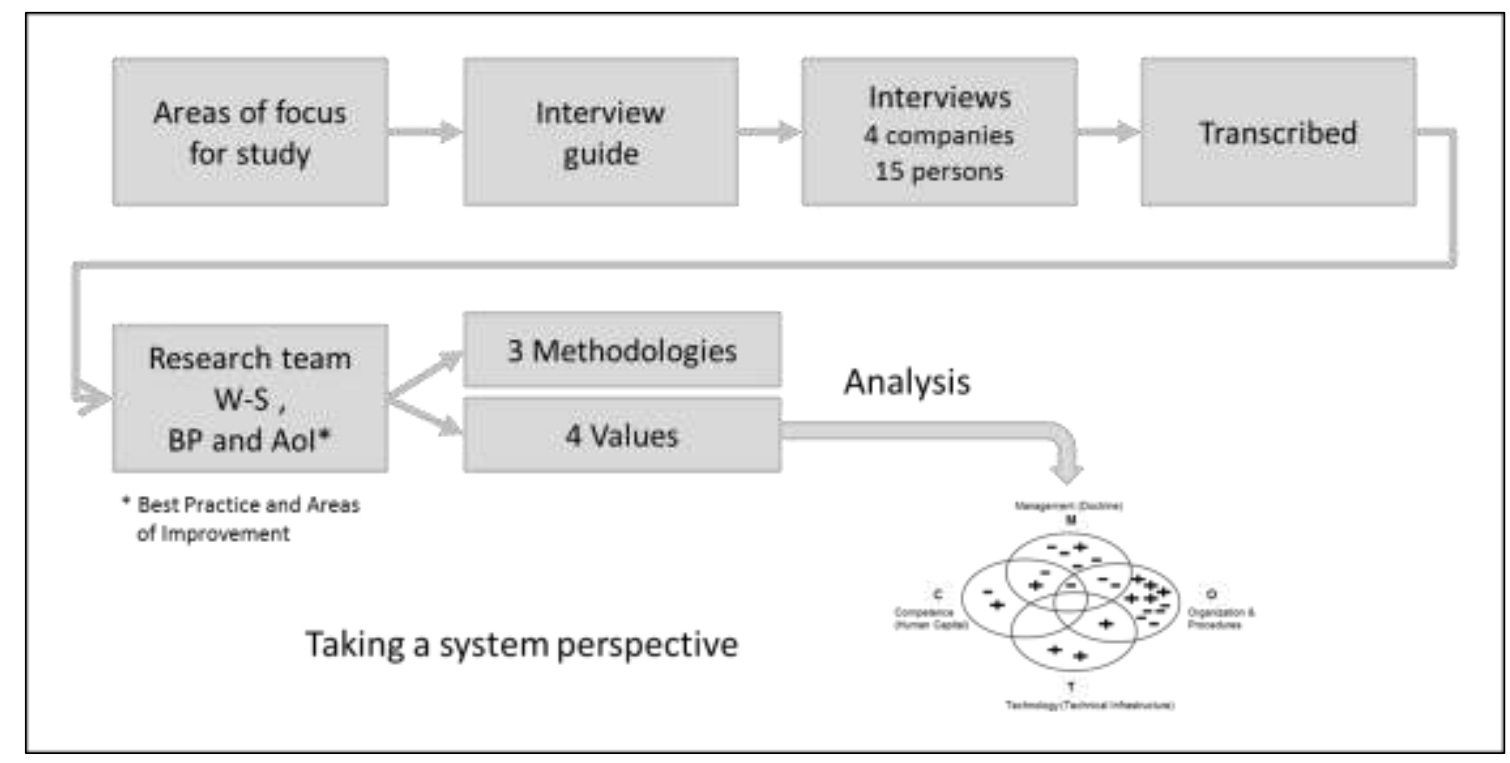

Figure 2 - The research methodology for the study 


\section{RESULTS AND ANALYSIS}

The results from the study are presented in the section below, distributed into the predefined Lean values: Customer focus, Long-term thinking, System view and Continuous improvements. Best practice and areas of improvement are presented along with the results from the analyses from a wider perspective i.e. according to the Synergy-4 model.

\subsection{Customer focus}

To have a customer focus is, in this paper, defined as having a clear view of the customer, i.e. everybody concerned within the company knows for whom they create value. In addition, the company also works actively with finding out what the customer wants and how the customer experiences the delivered products and services.

In Table 1 below, the identified best practices and areas of improvement within customer focus are presented.

Table 1 - Best practices and areas of improvement within customer focus

\begin{tabular}{|c|c|}
\hline Best practice & S-4 \\
\hline Carries out structured customer surveys (questionnaires) plus personal interviews & $\mathrm{O}$ \\
\hline The customer is involved when it comes to bigger projects & $\mathrm{O}$ \\
\hline $\begin{array}{l}\text { A process exists for carrying out and handling the results from customer surveys and } \\
\text { giving feedback to the customer }\end{array}$ & $\mathrm{O}$ \\
\hline Calls the customer and asks what they think of the company's products & $\mathrm{O}$ \\
\hline Using a user group early in the development process & $\mathrm{O}$ \\
\hline $\begin{array}{l}\text { There is a structured way of having contact (continuously calling the customers) and } \\
\text { documenting customer contacts (customer database) }\end{array}$ & $\mathrm{O}$ \\
\hline Using social media to get input from the customer & $\mathrm{T}$ \\
\hline $\begin{array}{l}\text { There are a number of interfaces with the customer and they work in a common } \\
\text { system }\end{array}$ & $\mathrm{T}$ \\
\hline The work with defining quality in customer documentation has been started & M \\
\hline Involves the internal customer in evaluation of the processes & $\mathrm{M}, \mathrm{C}$ \\
\hline $\begin{array}{l}\text { The technical communicator gets the opportunity to meet the customer during } \\
\text { customer training sessions; they can then bring feedback back and update the TC (in } \\
\text { this case as trainers) }\end{array}$ & $\mathrm{C}$ \\
\hline Areas of improvement & S-4 \\
\hline The external customer surveys do not measure TC & $\mathrm{O}$ \\
\hline Lack of time when it comes to carrying out what the customer asks for & M \\
\hline Lack of structure when it comes to handling feedback from the customers, e.g. at & $\mathrm{O}$ \\
\hline
\end{tabular}




\begin{tabular}{|l|l|}
\hline exhibitions and visits to the retailers & \\
\hline $\begin{array}{l}\text { Customer needs are not taken into account when the service handbook is being } \\
\text { produced }\end{array}$ & $\mathrm{O}, \mathrm{M}$ \\
\hline Lack of 'test drivers' of TC & $\mathrm{O}, \mathrm{M}$ \\
\hline A structured way of handling customer feedback is missing & $\mathrm{O}$ \\
\hline $\begin{array}{l}\text { There is a need for the organization to clarify what quality in TC and customer } \\
\text { documentation is }\end{array}$ & $\mathrm{M}$ \\
\hline $\begin{array}{l}\text { There are many different channels into the organization from customers but } \\
\text { coordination and structure are missing }\end{array}$ & $\mathrm{O}$ \\
\hline The external customer perspective is missing when it comes to defining quality in TC & $\mathrm{M}$ \\
\hline It is unclear who the customer is (the one who pays or the user) & $\mathrm{C}, \mathrm{M}$ \\
\hline Hard to get feedback from the customer especially from the user & $\mathrm{O}, \mathrm{C}$, \\
\hline There is a need for better understanding of customer needs & $\mathrm{M}$ \\
\hline $\begin{array}{l}\text { Considerable focus on the product in the customer interface. The connection to TC is } \\
\text { missing }\end{array}$ & $\mathrm{O}$ \\
\hline The requirements on TC are unclear & $\mathrm{M}$ \\
\hline
\end{tabular}

The way the organization looks upon TC effects how the organization works with customer demands, quality and also the way in which the customer is viewed. The study indicates a lack of clarity as to who the TC customer is, which from a Lean perspective is problematic since it is the customer's needs, expectations and demands that are to be fulfilled (Womack and Jones, 2003). This lack of clarity consists of several parts. In some cases, the person ordering the product is not the same as the user of the product and the TC, and this leads to a lack of access to, and sometimes even knowledge of, who is using the TC. The contact with the customer can also be regulated through a contract.

Most of the studied organizations have many different interfaces with their customers and gather a lot of feedback which is seen as a positive aspect. On the other hand, a structured way of handling these is missing, which in turn affects how the organizations can work with continuous improvements and drive organizational learning (Liker, 2004).

There are some examples of involving the customer in the development stage of the products, which is seen as positive. In some cases, a user group is involved in the development process, which can be interpreted as an example of a long-term customer perspective. This can be seen as a part of long-term thinking, which is an important factor for success according to Bicheno and Holweg (2009).

In analyzing the result according to Synergy-4, most of the best practices found are in the sphere of organization (see Figure 3). However, there are best practices present in all of the spheres and also in the overlapping spheres of management 
and competence and of organization and technology. The areas of improvement are also in all spheres with a main focus in organization. There are no areas of improvement identified in the sphere of technology. The areas of improvement are also in the overlapping spheres of competence, management and organization.

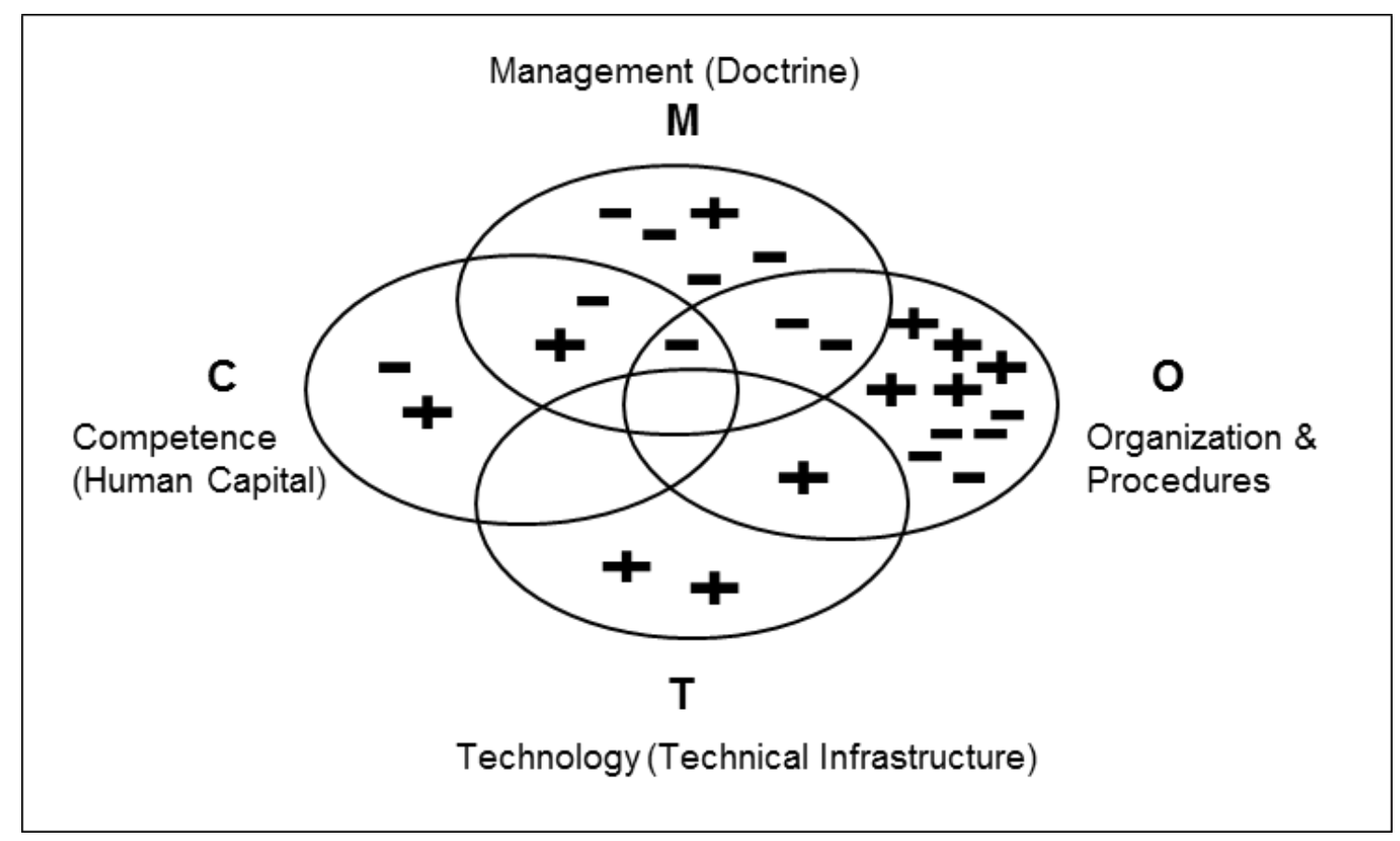

Figure 3 -Categorized best practices (+) and areas of improvement (-) within customer focus according to Synergy-4

Table 2 - Best practices and areas of improvement within Long-term thinking

\begin{tabular}{|l|l|}
\hline Best practice & S-4 \\
\hline Initiated a structured way of working with strategy for the company (2020) & $\mathrm{M}, \mathrm{O}$ \\
\hline A structured way of starting to apply Lean exists, initiated by the co-workers & $\begin{array}{l}\mathrm{O}, \mathrm{C}, \\
\mathrm{M}\end{array}$ \\
\hline Objectives deployed in the organization & $\mathrm{O}$ \\
\hline Areas of improvement & $\mathrm{S}-\mathbf{4}$ \\
\hline No specific objectives for TC & $\mathrm{M}$ \\
\hline Lack of configuration management & $\mathrm{T}$ \\
\hline $\begin{array}{l}\text { An explicit strategy for how to work with TC consultants is missing (if consultants are } \\
\text { wanted) }\end{array}$ & $\mathrm{M}$ \\
\hline Lack of clear Lean focus & $\mathrm{M}$ \\
\hline The organization's objectives need to be clarified & $\mathrm{M}$ \\
\hline
\end{tabular}




\subsection{Long-term thinking}

Long-term thinking is understood as having a long-term perspective in a company and is characterized by having a common and agreed vision for the company, long-term objectives and values and principles that permeate the whole company. The decisions taken are not only based on short-term economic profit but will ultimately benefit the customers, co-workers and the society as a whole.

In Table 2, the identified best practices and areas of improvement within Longterm thinking are presented. Long-term thinking seems to be a general area in need of improvement since findings both within best practice and areas of improvement are few. This could also mirror the fact that there were rather few questions in the interview regarding long-term thinking. A general problem in connection to long-term thinking seems to be that every project is being carried out in partial isolation. This shows that there is no focus on the organization as a whole as claimed by Womack and Jones, (2003). In other words, general objectives for the whole company have not been clarified before paying attention to the parts. In most companies in the study, the overall work with strategy and objectives is not followed by a breaking down of objectives, thus making it possible for technical communicators to see their contribution. This affects both the opportunity for more long-term planning of their work and the knowledge of how they can contribute to the whole. One area of improvement that has been identified concerns configuration management (Eriksson and Öberg, 2013, p. 10). A lack of focus on configuration management can be seen as an indication that the organization lacks long-term thinking when it comes to service and maintenance.

The best practices found concerning long-term thinking are in the sphere of organization and in the overlapping spheres of organization, management and also competence (see Figure 4). The areas of improvement identified are in the spheres of management and technology. 


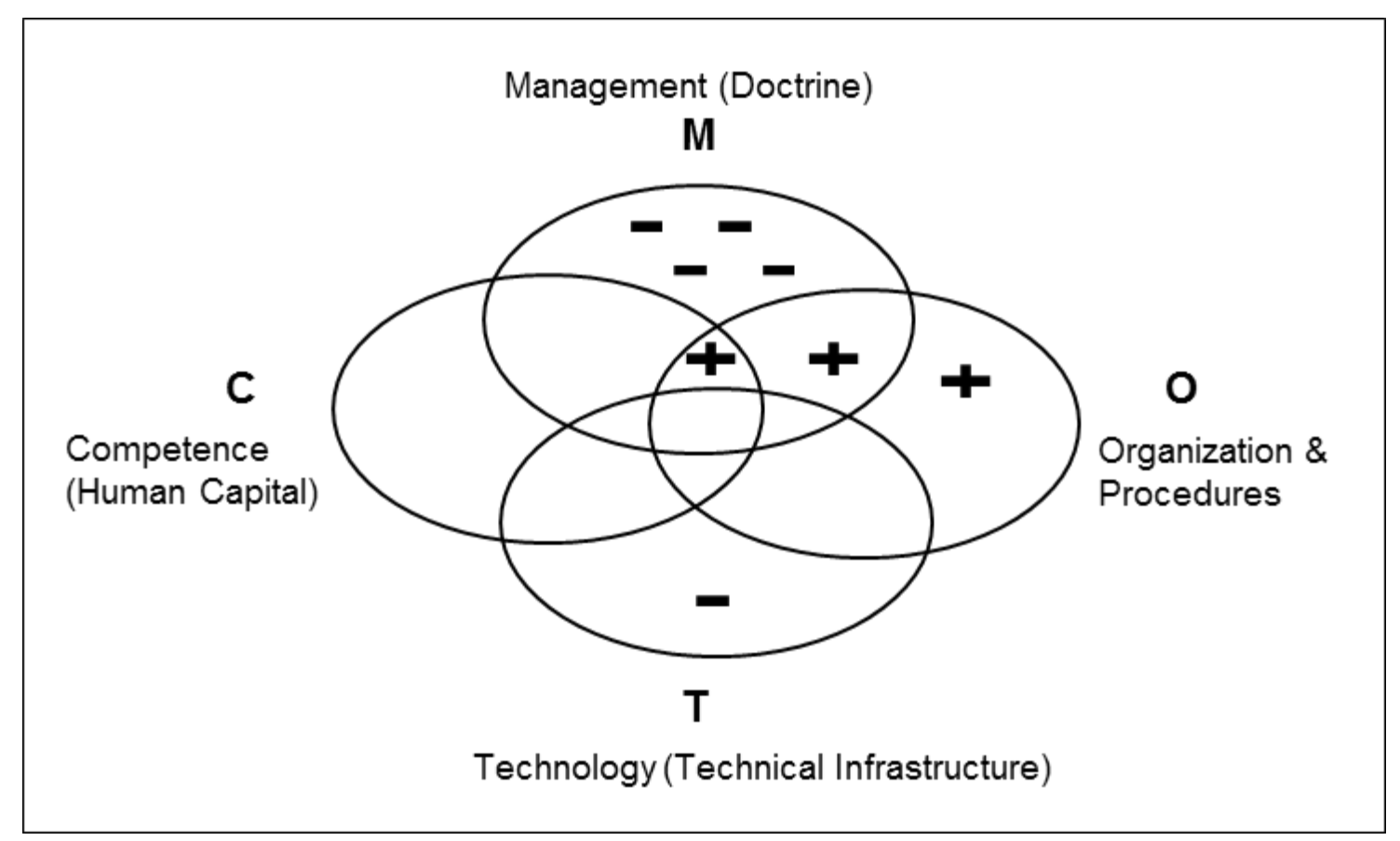

Figure 4-Categorized best practices (+) and areas of improvement (-) within long-term thinking according to Synergy-4

Two of the best practices found are in the overlapping spheres, and one of them was in the overlapping area of three spheres (M, C, O). Regarding long-term thinking, there is a need for a system view and best practices in the overlapping areas are essential.

\subsection{System view}

A system view is seen as a company's views on and ways of working with the entirety, the whole system, i.e. to take this totality into consideration when descriptions are made and objectives are being set. Customers, suppliers and society as a whole should be taken into consideration.

In Table 3 below, the identified best practices and areas of improvement within system view are presented.

Table 3 - Best practices and areas of improvement within system view

\begin{tabular}{|l|l|}
\hline Best Practice & S-4 \\
\hline Close cooperation between support and design and design and TC department & C, O, M \\
\hline Possibility to print TC themselves & T \\
\hline Trains the customers to reduce the pressure on support & C \\
\hline $\begin{array}{l}\text { There are many interfaces with the customers and the organization works in one } \\
\text { common system }\end{array}$ & T \\
\hline Initiated the documentation of their processes & O \\
\hline
\end{tabular}




\begin{tabular}{|l|l|}
\hline Modularization of TC (system, methodologies and mindset are coherent) & T \\
\hline Work together in teams where many different competences are included & C \\
\hline Areas of improvement & S-4 \\
\hline There is a need for more cooperation with the suppliers. & M \\
\hline The process for consultant procurement is complicated and time-consuming & O \\
\hline $\begin{array}{l}\text { The use of consultants creates a distance and the cooperation between competences } \\
\text { is made more difficult }\end{array}$ & C \\
\hline There is a need to involve the co-workers in the development of the processes & M, O \\
\hline A lack of focus on the products' lifecycle & M,O,C,T \\
\hline Lack of structure for learning from each other between different projects & C \\
\hline
\end{tabular}

A number of best practices were identified in the category of system view. By producing the TC themselves, as well as by training the customers, increased value can be obtained. Modularization is another example of having a system view since a well-carried out modularization brings about an overall view from design to production, which in turn enables more effective processes. The effectiveness in these cases affects translations, ordering spare parts as well as simplifying repairs. The identified cooperation between support and design and the TC department is also considered a good example of having a system view since all of these parts affect the company's ability to effectively produce overall solutions for the customer. This is important in the creation of value for the customer, which, according to Emiliani (2010), is central in Lean. When it comes to areas of improvement, it becomes obvious that the companies using consultants for their production of TC have a special set of problems. Purchasing TC is more time-consuming, it creates a distance and it becomes an obstacle to learning between projects. This in turn affects the work with continuous improvements which, along with learning from mistakes and continuous learning, are the contributions that Lean can make according to Bicheno and Holweg (2009).

The best practices found were in the spheres of organization, competence and technology (see Figure 5). There was also one best practice found in the overlapping area of competence, management and organization. The improvement was in the areas of organization, management and competence and also in the overlapping area of competence, management and organization. There is one area of improvement identified in the point where all the spheres overlap. Synergy effects and the combination of all spheres would be essential for factors concerning the system view. 


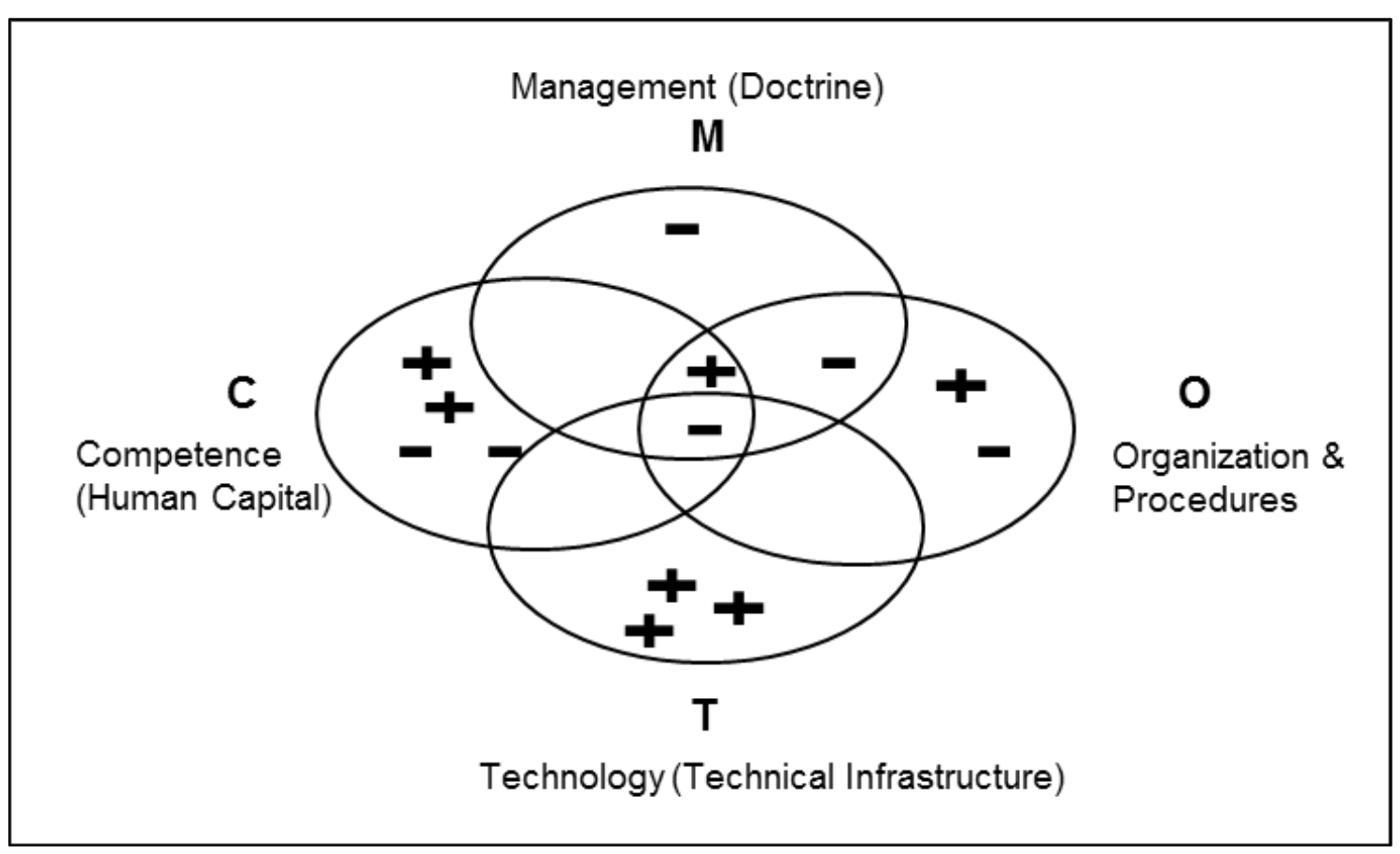

Figure 5-Categorized best practices (+) and areas of improvement (-) within system view according to Synergy-4

\subsection{Continuous improvements}

Continuous improvements are defined in the same way as Liker's (2004) 4P pyramid, at the top of which is Problem Solving (Continuous Improvement and Learning).

In Table 4 below, the identified best practices and areas of improvement within continuous improvements are presented.

Table 4 - Best practices and areas of improvement within continuous improvements

\begin{tabular}{|l|l|}
\hline Best practice & $\mathrm{S}-\mathbf{4}$ \\
\hline Close cooperation between support and design and design and TC department & $\begin{array}{l}\mathrm{C}, \mathrm{O}, \\
\mathrm{M}\end{array}$ \\
\hline Suggestions for improvement are always welcome & $\mathrm{C}, \mathrm{M}$ \\
\hline The web is a channel for TC and can continuously be updated & $\mathrm{T}$ \\
\hline Process for handling feedback from the customer exists (from training) & $\mathrm{O}$ \\
\hline Methodologies for working with improvements of documents exist & $\mathrm{O}$ \\
\hline Internal personnel working with verification of feedback of improvements on TC & $\mathrm{O}$ \\
\hline $\begin{array}{l}\text { Structured way of working with continuous improvements (including TC) } \\
\text { There is a method for signaling problems (where the whole value chain gets the } \\
\text { signal) }\end{array}$ & $\mathrm{O}$ \\
\hline
\end{tabular}




\begin{tabular}{|l|l|}
\hline Structured way of working with continuous improvements exists & $\mathrm{O}$ \\
\hline Simplification of ways of working is being carried out (internally) & $\mathrm{O}$ \\
\hline Areas of improvement & $\mathrm{S}-\mathbf{4}$ \\
\hline Methods for handling needs for change of TC products is missing & $\mathrm{O}$ \\
\hline A need for involving the co-workers in the development of the processes & $\mathrm{C}, \mathrm{M}$ \\
\hline Methodologies for working with improvement of documents are needed & $\mathrm{O}$ \\
\hline The process maps are not being fully utilized for managing the organization & $\mathrm{M}$ \\
\hline Unclear methodologies for updating TC & $\mathrm{O}$ \\
\hline
\end{tabular}

Concerning continuous improvements, the picture is similar to that of customer focus. That is, there are several examples of a change-friendly climate and many available channels, but methodologies for handling the suggestions are missing. In the long run, this is not good since it is important that the persons leaving suggestions also get feedback that these suggestions lead to improvements. This affects the quality work concerning TC since listening to the users should be the issue that the organization should have as their highest priority according to HartDavidson (2013). There are also many good examples of sections of a company having routines for working with continuous improvement but where they had not been able to spread this throughout the whole company.

In the category of continuous improvements, most of the best practices and areas of improvement are in the sphere of organization. However, one of the best practices is in the overlapping area of competence, management and organization. There is also one best practice and one area of improvement found in the overlapping area of competence and management. 


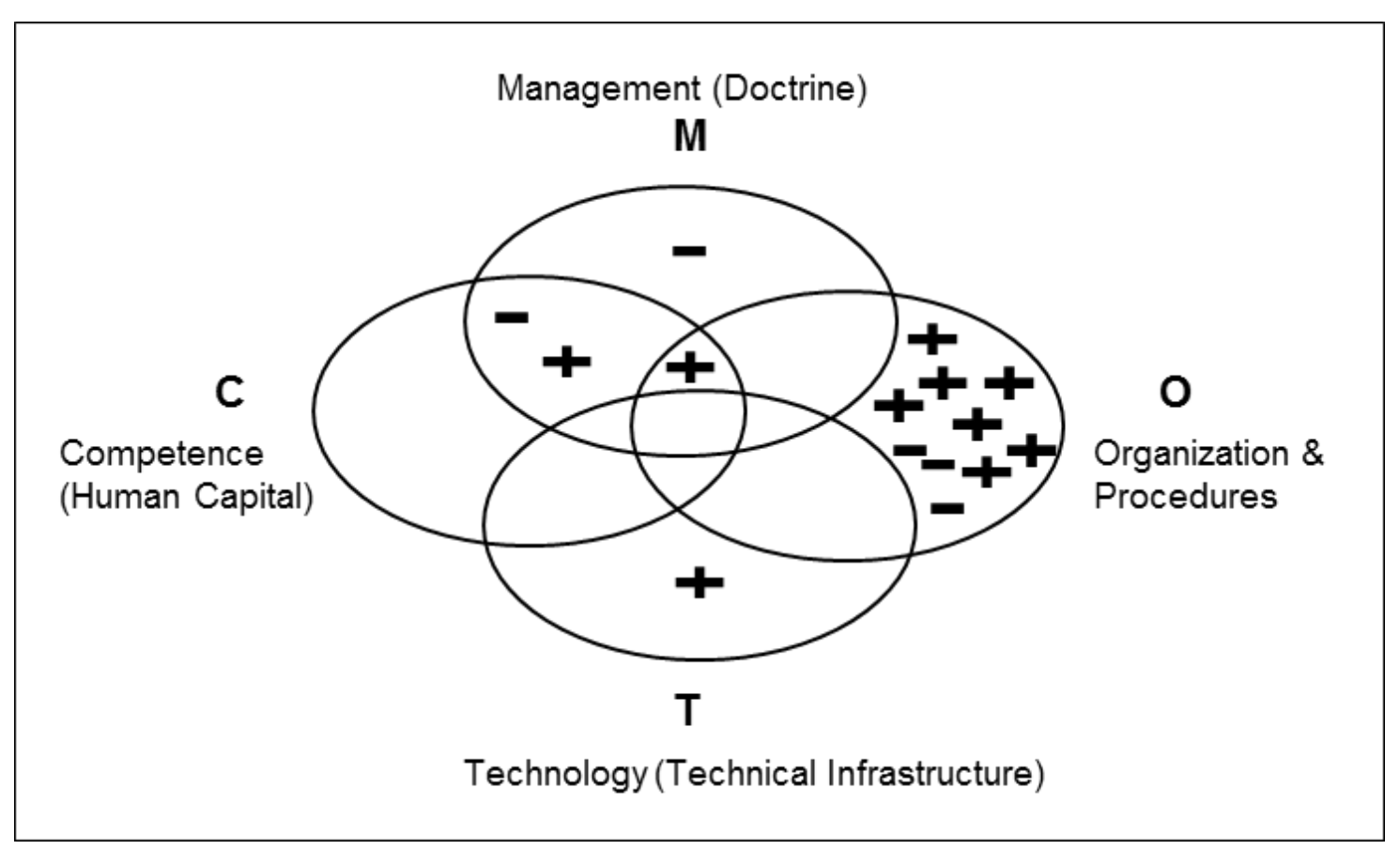

Figure 6-Categorized best practices (+) and areas of improvement (-) within continuous improvement according to Synergy-4

\section{DISCUSSION AND CONCLUSIONS}

There are best practices and areas of improvement identified in the overlapping areas of Synergy-4 in all categories. There are several areas of improvement identified in two of three overlapping areas (see Figure 7). The 'size' of the circles in the figure represents the number of best practices or areas of improvement within each Lean value and with regards to the different spheres or the overlapping of spheres. For example, there are five cases of best practices from the value Customer Focus categorized as the sphere Organizations and Procedures but only one from the value System view. The areas of improvement found in the overlapping area of all four spheres concern the need for a focus on the whole lifecycle of the product and indicate the need for a system view and synergy in the area of customer-adapted TC. A focus on the whole lifecycle of the product with the different customers present during the whole life of a product demands a holistic view embracing all the spheres of an organization. 


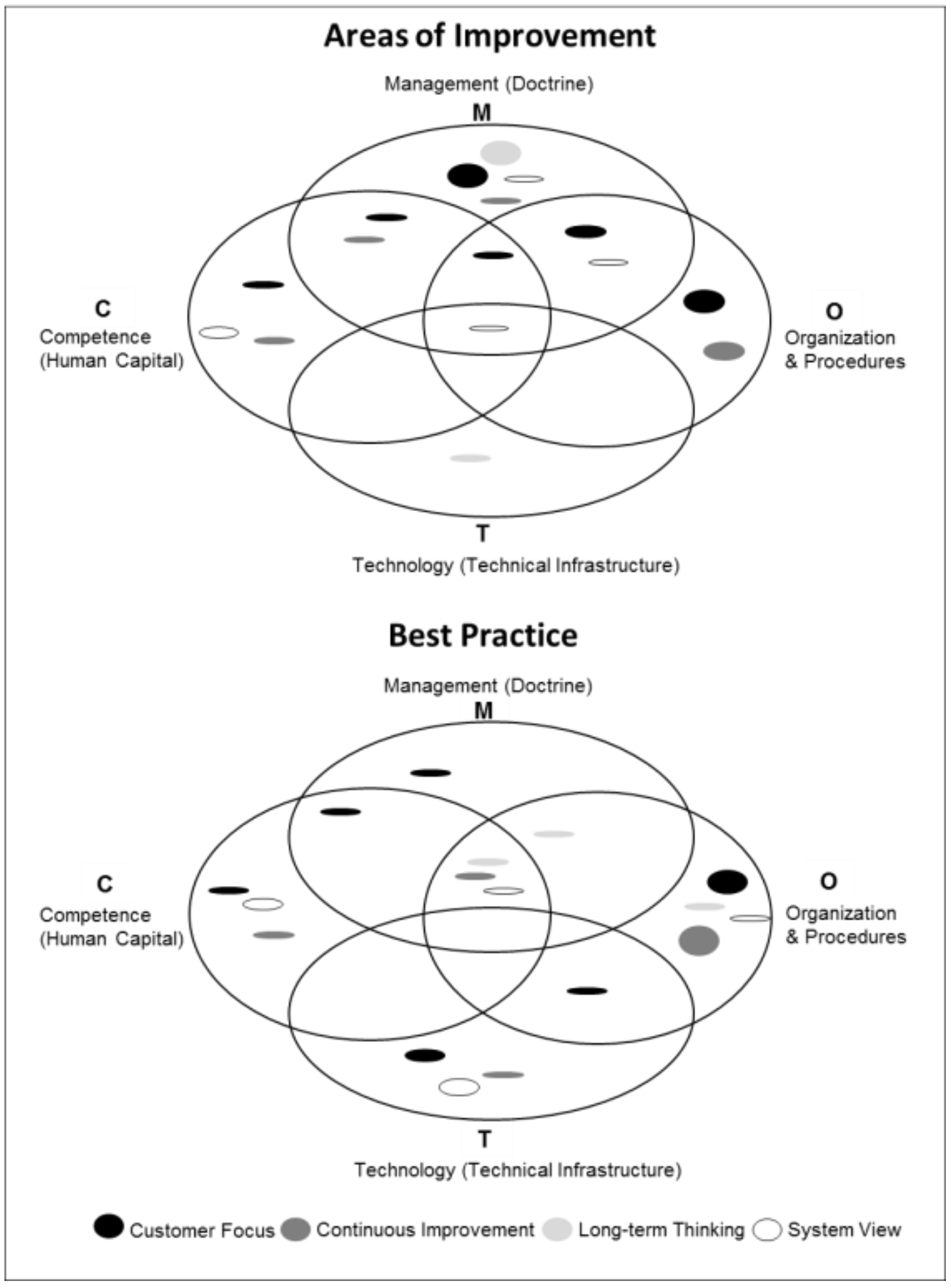

Figure 7 - Categorized Areas of Improvement and Best Practices within all categories according to Synergy-4

Most of the best practices and areas of improvement identified in the overlapping areas of competence, management, and organization concern cooperation between the different stakeholders of the product/TC. Cooperation between 
different actors holding different competences and knowledge indicates the need for competence exchange and learning. If all actors involved have the same information through e.g. competence development and learning, synergy effects will be reached. The organization should strive towards a learning organization built on continuous improvement and respect for people, which is the ultimate goal of Lean. One suggestion to fulfill the need to spread the work throughout the whole company is to work with the area of improvement concerning the need for involving the co-workers in the development of the processes. It is important to address this since it is most often the co-workers that have the solutions. Not involving them in the improvement work makes it impossible to create a 'true' learning organization, which in Lean is seen as the foundation for a climate of continuous improvement and development.

There are only a few best practices and areas of improvement identified in the sphere of technology for all the categories. One explanation of this may be the focus of the study. The focus was on customer-adapted TC and as such was not technical. The categories identified for the study were intended to focus on Lean and a technical focus of this kind is not present to a large extent in Lean. However, technology is an important factor that is present in society and many organizations today.

The previously identified problem of the customer perspective in the production of TC, that is to say that TC is not seen as part of the customer offering in some companies, suggests that there is a lack of a system view in the customer offering. A system view would entail a clearer picture of the real customers of TC and who those customers are. This will make it easier to measure and evaluate the opinions of TC amongst them and thereby increase the understanding of how TC could enhance the value of the total offer. A combination of the spheres in an organization leads to synergetic effects (Holmberg, 2001). High-quality TC would also entail synergetic effects. TC affects different kinds of customers and several parts of the organization. An increase in the competence, knowledge and awareness of TC makes it a part in all the spheres in an organization. This would contribute to synergetic effects in the whole organization and the status of TC would be improved.

When examining the specific Lean values one can conclude that most of the examples from both best practice and areas of improvement are within the sphere of organization and procedures with regards to Continuous improvement and Customer focus. This would seem to suggest that there are methodologies in place yet there is little evidence of the sphere that reflects management. This is also mirrored in the values Long-term thinking and System view. This result indicates that the prospect of creating a culture based on Lean values can be difficult due to the lack of a leadership dimension which is necessary to develop a new culture (Schein, 2006).

Borglund, Slumpi and Öberg (2010) claim that research concerning the synergies in the Synergy-4 model has not yet been performed. In this study, several synergies have been identified and this can be seen as an attempt to counteract 
this lack of research. Lean has been proven to be a method for identifying possible synergies and it could therefore create potential for an enrichment and further development of the Synergy-4 model. The model can, for instance, be used when implementing different improvement initiatives to analyze the utility from a system perspective. Borglund, Slumpi and Öberg (2010) claim that the Synergy-4 approach has to be considered at an early stage when designing the study. However, if the model is present in the design, there is a risk that the focus will be on the spheres and that the overlapping areas and the synergy present will be overlooked. Additionally, this study has proved that the Synergy-4 approach does not have to be already present in the design to be able to identify synergies.

Since the categories identified for the study show that a technical focus is not present in Lean, Synergy-4 could help to focus on technical solutions and thereby add another perspective on how to strengthen values within Lean. The results from the study confirm that TC has a low status in the studied organizations as stated by Bank, Löfstedt and Nyström (2013) but, the results also indicate that the focus on Lean and the implementation of Lean values could enhance the status of TC.

\section{REFERENCES}

Asproth, V., 2011. Slutrapport för projektet Teknikinformationscentrum 20072011. Projektet TIC, Mittuniversitetet, Institutionen för informationsteknologi och medier. [online] Available at: www.miun.se/ticprojektet [Accessed 2015.08.20].

Bank, B., Löfstedt, U. and Nyström, C.A., 2013. Projekt TIC II Kompetensförsörjning för lärande organisationer med fokus på TI. Mittuniversitetet, Institutionen för informationsteknologi och medier. [online] Available at: www.miun.se/ticprojektet [Accessed 2015.08.20].

Borglund, E, Slumpi, T. P. and Öberg. L-M., 2010. Applying Synergy-4 in Informatics Research - Some Reflections. In V. Asproth, ed. (2011) Challenges for the future in an ICT context. Mid Sweden University, pp- 151-165.

Bäckström, I., Ingelsson, P., Löfstedt, U., Mårtensson, A. and Öberg, L-M., 2014. Kvalitetsarbete inom teknikinformation - Goda exempel och utvecklingsbehov. Rapport Mittuniversitetet, Projekt Kundanpassad teknikinformation - KATI.

Bicheno, J. and Holweg, M., 2009. The Lean toolbox: The essential guide to Lean transformation. Buckingham: PICSIE Books.

Emiliani, B., 2010. Moving forward faster: the mental evolution from fake Lean to REAL Lean. Wethersfield, Conn.: The Center for Lean Business Management, LLC

Emiliani, M. L., 1998. Lean behaviors. Management Decision, 36(9), pp.615631. 
Eriksson, M. and Öberg, L-M., 2013. Configuration Management i teknikinformationens tjänst - en antologi. Sundsvall: Mittuniversitetet.

Hart-Davidson W., 2013. What are the Work Patterns of Technical Communication? In J. Johnson-Eilola, J., S.A. Selber, eds. 2013. Solving problems in technical communication. Chicago, IL: University of Chicago Press.

Holmberg, S. C., 2001. Taking Synthegrity-4 from Assumption Mode to Reflection Mode. System Research and Behavioral Science, 18, pp.127-135.

Johnson-Eilola, J. and Selber, S.A, 2013. Solving problems in technical communication. Chicago, IL: University of Chicago Press.

Liker, J. K., 2004. The Toyota Way: 14 management principles from the world's greatest manufacturer. New York: McGraw-Hill.

Modig, N. and Åhlström, P., 2012. This is Lean: Resolving the efficiency paradox. Stockholm: Rheologica publishing Bulls Graphics AB.

Nyström, A.C, Asproth, V., 2013. Virtual Teams - Support for Technical Communication? Journal of organizational transformation and social change, 10(1), pp.64-80.

Petersen, K. and Wohlin, C., 2011. Measuring the flow in Lean software development. Software - Practice and Experience, 41(9), pp.975-996.

Rother, M. and Shook, J., 2004. Lära sig se. Att kartlägga och förbättra värdeflöden för att skapa mervärde och eliminera slöseri. Stockholm: Edita Norstedts Tryckeri

Schein, E. H., 2006. Organizational culture and leadership. (3. ed.). San Francisco: Jossey-Bass.

Seddon, J., 2005. Freedom from command \& control: Rethinking management for Lean service. New York: Productivity Press.

Selfe, R.J. and Selfe, C.L, 2013. What are the Boundaries, Artifacts, and Identities of Technical Communication? In J. Johnson-Eilola, J., S.A. Selber, eds. 2013. Solving problems in technical communication. Chicago, IL: University of Chicago Press

Womack, J. P. and Jones, D. T., 2003. Lean thinking: banish waste and create wealth in your corporation. London: Free Press Business.

Öberg, L.-M., 2009. Krav och kvalitetskrav inom teknisk information med fokus på offentlig upphandling. [online] Available at: www.miun.se/ticprojektet.

Öberg, L.-M., 2011. Krav och kvalitetskrav inom teknisk information -från användar- och beställarperspektiv. [online] Available at: www.miun.se/ticprojektet [Accessed 2015.08.20]. 


\section{ABOUT AUTHORS}

Pernilla Ingelsson, $\mathrm{PhD}$, Department of Quality Technology and Management, Mid Sweden University, Östersund, Sweden, e-mail: pernilla.ingelsson@ miun.se

Ulrica Löfstedt, PhD, Department of Computer and Systems Science, Mid Sweden University, Östersund, Sweden, e-mail: ulrica.lofstedt@ @iun.se

Ingela Bäckström, Associate Professor Department of Quality Technology and Management, Mid Sweden University, Östersund, Sweden, e-mail: ingela.backstrom@miun.se

Lena-Maria Öberg, PhD, Department of Computer and Systems Science, Mid Sweden University, Östersund, Sweden, e-mail: lena-maria.oberg@miun.se 